\title{
Pilot study testing a European human biomonitoring framework for biomarkers of chemical exposure in children and their mothers: experiences in the UK
}

\author{
Karen Exley • Dominique Aerts • Pierre Biot - Ludwine Casteleyn • \\ Marike Kolossa-Gehring • Gerda Schwedler • Argelia Castaño • \\ Jürgen Angerer • Holger M. Koch • Marta Esteban • Birgit K. Schindler • \\ Greet Schoeters • Elly Den Hond • Milena Horvat • Louis Bloemen • \\ Lisbeth E. Knudsen • Reinhard Joas • Anke Joas • Ovnair Sepai
}

Received: 2 July 2014 / Accepted: 3 December 2014

(C) Her Majesty the Queen in Right of United Kingdom 2015

\begin{abstract}
Exposure to a number of environmental chemicals in UK mothers and children has been assessed as part of the European biomonitoring pilot study, Demonstration of a Study to Coordinate and Perform Human Biomonitoring on a European Scale (DEMOCOPHES). For the Europeanfunded project, 17 countries tested the biomonitoring guidelines and protocols developed by COPHES. The results from the pilot study in the UK are presented; 21 school children aged 6-11 years old and their mothers provided hair samples to measure mercury and urine samples, to measure cadmium, cotinine and several phthalate metabolites: mono(2-ethyl-5hydroxyhexyl)phthalate (5OH-MEHP), mono(2-ethyl-5-oxohexyl)phthalate (5oxo-MEHP) and mono(2ethylhexyl)phthalate (MEHP), mono-ethyl phthalate (MEP),
\end{abstract}

Responsible editor: Philippe Garrigues

K. Exley $(\square) \cdot$ O. Sepai
Centre for Radiation, Chemical and Environmental Hazards, Public
Health England, Chilton, Oxfordshire OX11 0RQ, UK
e-mail: karen.exley@phe.gov.uk
D. Aerts · P. Biot
Federal Public Service Health, Food Chain Safety and Environment,
Brussels, Belgium
L. Casteleyn
University of Leuven, Leuven, Belgium

M. Kolossa-Gehring $\cdot$ G. Schwedler

Federal Environment Agency (UBA), Berlin, Germany

\author{
A. Castaño $\cdot$ M. Esteban \\ Instituto de Salud Carlos III (ISCIII), Madrid, Spain
}

mono-iso-butyl phthalate (MiBP), mono-benzyl phthalate (MBzP) and mono-n-butyl phthalate (MnBP). Questionnaire data was collected on environment, health and lifestyle. Mercury in hair was higher in children who reported frequent consumption of fish (geometric mean $0.35 \mu \mathrm{g} / \mathrm{g}$ ) compared to those that ate fish less frequently $(0.13 \mu \mathrm{g} / \mathrm{g}, p=0.002)$. Cadmium accumulates with age as demonstrated by higher levels of urinary cadmium in the mothers (geometric mean $0.24 \mu \mathrm{g} / \mathrm{L})$ than in the children $(0.14 \mu \mathrm{g} / \mathrm{L})$. None of the mothers reported being regular smokers, and this was evident with extremely low levels of cotinine measured (maximum value $3.6 \mu \mathrm{g} / \mathrm{L}$ in mothers, $2.4 \mu \mathrm{g} / \mathrm{L}$ in children). Very low levels of the phthalate metabolites were also measured in both mothers and children (geometric means in mothers: $5 \mathrm{OH}-$

J. Angerer $\cdot$ H. M. Koch • B. K. Schindler

Institute for Prevention and Occupational Medicine of the German Social Accident Insurance, Institute of the Ruhr-Universitat Bochum (IPA), Bochum, Germany

G. Schoeters $\cdot$ E. Den Hond

Environmental Risk and Health Unit, Flemish Institute for

Technological Research (VITO), Mol, Belgium

M. Horvat

Jožef Stefan Institute, Ljubljana, Slovenia

L. Bloemen

Environmental Health Science International, Hulst, Netherlands

L. E. Knudsen

University of Copenhagen, Copenhagen, Denmark

R. Joas $\cdot$ A. Joas

BiPRO GmbH, Munich, Germany 
MEHP $8.6 \mu \mathrm{g} / \mathrm{L}$, 5oxo-MEHP $5.1 \mu \mathrm{g} / \mathrm{L}$, MEHP $1.2 \mu \mathrm{g} / \mathrm{L}$, MEP $26.8 \mu \mathrm{g} / \mathrm{L}$, MiBP $17.0 \mu \mathrm{g} / \mathrm{L}$, MBzP $1.6 \mu \mathrm{g} / \mathrm{L}$ and MnBP $13.5 \mu \mathrm{g} / \mathrm{L}$; and in children: 5OH-MEHP $18.4 \mu \mathrm{g} / \mathrm{L}$, 5oxoMEHP $11.4 \mu \mathrm{g} / \mathrm{L}$, MEHP $1.4 \mu \mathrm{g} / \mathrm{L}$, MEP $14.3 \mu \mathrm{g} / \mathrm{L}$, MiBP $25.8 \mu \mathrm{g} / \mathrm{L}$, MBzP $3.5 \mu \mathrm{g} / \mathrm{L}$ and MnBP $22.6 \mu \mathrm{g} / \mathrm{L}$ ). All measured biomarker levels were similar to or below populationbased reference values published by the US National Health and Nutrition Examination Survey (NHANES) and Germany's GerES surveys. No results were above available health guidance values and were of no concern with regards to health. The framework and techniques learnt here will assist with future work on biomonitoring in the UK.

Keywords DEMOCOPHES - Biomonitoring - Cotinine . Mercury $\cdot$ Phthalates $\cdot$ Cadmium $\cdot$ Environmental exposure

\section{Introduction}

In the UK, public health risk assessment of exposure to environmental chemicals uses environmental monitoring of air, water and land to compare with environmental standards and guidelines. This can be extrapolated to provide information on possible exposures of a population, but it does not necessarily reflect actual levels of chemical uptake. Human biomonitoring (HBM) provides a more direct measure of actual personal exposure to environmental chemicals, but interpretation can be limited due to a lack of UK population based reference levels to compare with. There are some health-based projects that have contributed to the understanding of environmental chemical exposures in the UK population, such as the Avon Longitudinal Study of Parents and Children (ALSPAC), which has published, for example, on lead and mercury exposures in pregnancy (Golding et al. 2013; Taylor et al. 2013). A study for the UK population by Bevan and colleagues collected data to develop reference ranges for a number of environmental chemicals in widespread use including benzene, cadmium, mercury and naphthalene (Bevan et al. 2013). However, the UK at present does not have a National HBM programme for chemical exposures, and ideally, future studies would have protocols that enable the work to be comparable with other biomonitoring programmes (Exley 2014).

A number of countries have long-term national biomonitoring programmes such as the National Health and Nutrition Examination Survey in the US (NHANES), the German Environmental Survey (GerES), the HBM project in the Czech Republic (CZ-HBM) and the Flemish Environment and Health Study (FLEHS). These programmes have established reference values, tracked trends of chemical exposures over time and determined regional differences in contaminant levels. The results from these studies can be used to inform policy needs, to evaluate effectiveness of policy measures and to determine whether environmental exposures lead to biological effects (Becker et al. 2007; Centers for Disease Control and Prevention 2014; Černá et al. 2012; Schoeters et al. 2012).

In 2003, the EU identified the importance of HBM but recognised that despite a number of European countries actively involved in HBM, there was a lack of comparable data and so it recommended that protocols be harmonised (Commission of the European Communities 2003). To enable the collection of comparable HBM data throughout Europe, a framework and protocols were developed by the 'Consortium to Perform Human Biomonitoring on a European Scale' (COPHES). COPHES was formed in 2009 with European scientists and stakeholders from 27 European countries and funded by the European Union (EU). In 2010, 'Demonstration of a Study to Coordinate and Perform Human Biomonitoring on a European Scale' (DEMOCOPHES) involving 21 European countries started work on a pilot study, funded by the EU and participating countries, to test in 17 countries the harmonised approach and protocols developed by COPHES (Joas et al. 2012).

The aim of DEMOCOPHES was for each participating country to test the protocols by recruiting 120 children and their mothers to provide urine and hair samples to measure exposure to cadmium, mercury, phthalates and environmental tobacco smoke and to complete an exposure questionnaire. Cadmium in urine, mercury in hair and exposure to environmental tobacco smoke, assessed by the measurement of cotinine, were chosen because they are of public health concern and would allow the testing of different biological samples and organic and inorganic substances for which health-based guidance values or reference values are available. Phthalates, which are used as plasticisers and solvents and are found in flooring and wall coverings, personal care products, medical devices and food contact materials, were also included (Angerer et al. 2011; Becker et al. 2009; Hauser and Calafat 2005). Population exposure to phthalates is ubiquitous, and the major pathway of exposure of the general population is via the diet (Angerer et al. 2011; Becker et al. 2009; Hauser and Calafat 2005). Exposure to phthalates is assessed by analysis of their urinary metabolites (Koch et al. 2003; Silva et al. 2004). The phthalates chosen by the consortium to be studied were di(2-ethylhexyl) phthalate, di-n-butyl phthalate (DnBP), di-iso-butyl phthalate (DiBP) and butyl benzyl phthalate (BBzP), which are classified as reprotoxic so their use is restricted according to Directive 2005/84/EC (European Commission 2005), and diethyl phthalate (DEP). The UK was one of the participating countries in the pilot study, and this paper discusses the results from the UK, which assessed the exposure to these chemicals in 21 children and their mothers. 


\section{Methods}

The UK DEMOCOPHES pilot study protocol was based on the COPHES common European pilot study protocol with slight modifications (as listed below); discussion of the approach for designing the study has been published (Becker et al. 2013). The pilot study was cross-sectional in design and participating countries could recruit via population registries or by schools. In the UK, children (age group of 6 to 11 years) and accompanying mothers aged up to 50 years old (this is a slight modification to the COPHES protocol which recommended up to 45 years old) were recruited via schools and personal contacts around Stonehouse in Gloucestershire and Chilton in Oxfordshire. Twenty schools were approached for the study and three schools agreed to take part. Visits to these schools were arranged to talk to children and parents about the study, and information about the study was included in school newsletters. Invite letters were sent to the mothers of all eligible children (871 aged 6-11 years) through the school and/or email. Sampling ran from 30 January to 24 April 2012.

The inclusion criteria for the study were as follows: mother and child must have been living in the sampling area for the last 5 years. Only one child per mother (randomly selected) could be included in the study, the child must live most of the time ( $>16$ days/month) with the mother and none of the participants should have metabolic disturbances or abnormal urine excretion. Participants were asked to bring a firstmorning urine sample to an appointment at a local study centre, where they were asked to provide a hair sample and to answer a questionnaire of relevant exposure behaviours.

Information leaflets and consent forms were sent to participants in advance of the appointment along with urine sample containers (Starplex 80-mL polypropylene containers \#30071) in order to provide first-morning samples at home on the day of the appointment. The urine samples were stored at $4{ }^{\circ} \mathrm{C}$, before sending to the laboratory for aliquoting and analysis.

During the appointment at the study centre, the mother was asked to provide consent for themselves and their child to take part. Children were also given the opportunity to express their agreement to participate on an informed assent form, written in age-appropriate language. Then, the urine and hair samples of mother and child were collected, following the Standard Operating Procedure provided by the COPHES Quality Assurance Unit (Esteban et al. 2014). For the hair sampling, the hair was grasped from the middle of the back of the head and clipped out of the way. Several strands of hair were rolled up to form a lock and taped at distance from the root of about 5 to $6 \mathrm{~cm}$, and the sample was cut using stainless steel scissor as close to the scalp as possible; for hair shorter than $3.5 \mathrm{~cm}, 5-$ 10 strands of hair from different places on the back of the head were cut.
The questionnaire was performed as an interviewer-guided questionnaire with the mother. Developed by COPHES/ DEMOCOPHES, it contained questions concerning residential environment and residence, nutrition, smoking behaviour, occupation and socio-demography; some questions on sociodemographic aspects were adapted according to UK classifications. Short additional questions for the hair and urine collections were asked, which covered height and weight, time of last void, whether they had consumed seafood in the last $48 \mathrm{~h}$ and whether they had had any recent hair treatments.

The study was approved by the London Riverside South West Research Ethics Committee (Reference 11/LO/1383) prior to commencement of the study. The ethics committee recommended slight modifications to the protocol. These were (1) a booklet for general practitioners to advise them of the study and provide information on the follow-up management of participants including whether repeat testing of the chemicals under study was required. (2) The results letter for individual results was amended to only be sent to those with high levels, above guidance values, stating what the known risks of those levels were and whether the levels correlated with any known outcomes. The letter also stated whether repeat testing was required. However, under the Environmental Information Regulations in the UK, if participants requested their individual results, they would be provided.

The storage and retention of personally identifiable data were carried out in accordance with the Data Protection Act, 1998. All personal identifiable information was entered onto a password-protected database, and participants were referred to with a personal identification number.

\section{Sample handling}

On receipt, samples were logged in Health and Safety Laboratory's (HSL) Biological Monitoring Database and assigned unique sample numbers. Sample volumes were measured, and samples were split into three containers and stored frozen $\left(-20^{\circ} \mathrm{C}\right)$ until analysis. Subsamples that were sent to other laboratories for analysis were sent frozen, by courier. The remaining UK samples are stored at HSL. The urine samples have been filtered to remove any cells, a requirement for storage in order to comply with UK tissue storage requirements, and are stored at $-80{ }^{\circ} \mathrm{C}$. The hair samples are stored at room temperature, out of direct sunlight.

\section{Chemical analysis}

Urine samples were measured for cadmium, phthalate metabolites (mono-ethyl phthalate (MEP), mono(2-ethylhexyl) phthalate (MEHP), mono(2-ethyl-5-oxo-hexyl)phthalate phthalate (5-oxo-MEHP), mono(2-ethyl-5hydroxyhexyl)phthalate phthalate (5OH-MEHP), mono-isobutyl phthalate (MiBP), mono-n-butyl phthalate (MnBP) and 
mono-benzyl phthalate $(\mathrm{MBz} P))$, cotinine and creatinine to correct for urine dilution, and the hair samples were tested for mercury. Urinary creatinine concentrations were determined on all urine samples by the Jaffe alkaline picrate method (Cocker et al. 2011) on an ABX Pentra 400 (Horiba Diagnostics, Northampton, UK).

The analyses of mercury in hair, urinary cadmium and creatinine were carried out at the Health and Safety Laboratory in the UK. Mercury in hair was measured using a X7 Series 2 Thermo Fisher Scientific Inductively Coupled Plasma Mass Spectrometer (ICP-MS). The limit of quantification (LOQ) was $0.0225 \mu \mathrm{g} / \mathrm{g}$. Cadmium in urine was analysed using a X7 Series 2 Thermo Fisher Scientific Inductively Coupled Plasma Mass Spectrometer (ICP-MS). The LOQ was $0.004 \mu \mathrm{g} / \mathrm{L}$. Urinary phthalate metabolites were measured at the Flemish Institute of Technological Research (VITO) in Belgium using ultra-performance liquid chromatography tandem mass spectrometry (UPLC-MS/MS) (Waters Acquity UPLC-Waters Xevo TQ-S); the LOQ was $0.1-0.5 \mu \mathrm{g} / \mathrm{L}$, depending on the analyte. Cotinine analysis was carried out at the Umweltbundesamt in Austria using LC-MS/MS; the LOQ was $1.2 \mu \mathrm{g} / \mathrm{L}$.

The analyses were based on analytical standard operating procedures (SOPs) provided by the COPHES quality assurance unit (Angerer 2008; Blaszkewicz 2010; Müller 2005; Schramel 1999). The laboratories that analyzed the samples had successfully participated in the inter-laboratory comparability investigation (ICI), which was run to harmonise the analytical measures to improve the comparability of the analytical results, and the External Quality Assessment Scheme to improve the accuracy of the results (EQUAS), both of these were organised by COPHES/DEMOCOPHES (Schindler et al. 2014; Esteban et al. 2014).

\section{Statistical analysis}

Data was analysed with the SPSS statistical package (version 20). The mother and child pair counted as a case only if they gave informed consent, met the inclusion criteria, both provided a urine sample and a hair sample and answered the questionnaire. Values below the LOQ were replaced by $1 / 2$ LOQ. If more than $50 \%$ of the values for an analyte were below the LOQ, no means were calculated. The World Health Organization (WHO) recommends that urine samples with a creatinine concentration lower than $30 \mathrm{mg} / \mathrm{dL}$ or higher than $300 \mathrm{mg} / \mathrm{dL}$ be excluded from the analysis (WHO 1996); all the urine samples were between this range and so all were included in the analysis. For each biomarker, the data was stratified into relevant subgroups to study relevant confounders and investigate possible sources of exposure. Based on the numbers of participants within each subgroup, some analysis was only descriptive, and for the rest statistical analysis ( $t$ test or analysis of variance (ANOVA) after log transformation was possible. Themothers' data was compared with the children's data using the Spearman's rho or Pearson correlation coefficients, and all data was compared with HBM population based reference values and guidelines (where available) and other HBM studies.

\section{Results}

Of the 871 eligible child-mother pairs invited to take part in the study, just 22 replies were received, a $2.5 \%$ response rate. Details of the pilot study population are presented in Table 1 . Mercury was measured in hair samples, and cotinine, cadmium and phthalate metabolites were measured in urine samples from 21 children aged 6-11 years old and their mothers (one pair dropped out before sample collection).

\section{Mercury in hair}

Mercury levels in hair are shown in Table 2. Mercury was detected above the LOQ of $0.01 \mu \mathrm{g} / \mathrm{g}$ in all the study participants. Levels of mercury in hair was positively correlated in mothers and children; calculation of Spearman's rho correlation coefficient indicated a positive correlation of $0.68(p=$ $0.001)$. The geometric mean level of mercury measured in the mothers' hair $(0.16 \mu \mathrm{g} / \mathrm{g})$ was lower than the level measured in the children's hair $(0.19 \mu \mathrm{g} / \mathrm{g})$, and the maximum value measured for mercury in hair was just $0.44 \mu \mathrm{g} / \mathrm{g}$ in the mothers compared to $1.18 \mu \mathrm{g} / \mathrm{g}$ in the children. Over a third (38\%) of children reported eating fish on a regular basis, and mercury levels were significantly higher $(p=0.002)$ in these children who reported frequent fish consumption $(0.35 \mu \mathrm{g} / \mathrm{g})$ compared to those who ate fish less frequently $(0.13 \mu \mathrm{g} / \mathrm{g})$ and specifically sea fish consumption $(0.37$ and $0.16 \mu \mathrm{g} / \mathrm{g}$ respectively, $p=0.03$ ). Like the children, a third of mothers reported consuming fish on a regular basis, i.e. several times a week, but mercury levels were not significantly different to the mothers who reported eating fish less frequently. In addition to fish consumption, a number of other possible sources of mercury, including sources of other forms of mercury, were explored in the questionnaire, such as skin bleaching products and amalgam fillings. No participants reported using skin bleaching products, and there was no difference between participants with amalgam fillings compared to those without.

\section{Urinary cotinine}

Urinary cotinine provides a measure for recent exposure to nicotine as cotinine is an oxidised metabolite of nicotine and is excreted in the urine within 3-4 days of exposure (Benowitz 1996). There are no specific guidelines for cotinine levels, but persons with a value of more than $50 \mu \mathrm{g} / \mathrm{g}$ creatinine can be regarded as a smoker or a heavy exposed non-smoker (Riboli 
Table 1 Details of the pilot study participants in the UK

\begin{tabular}{|c|c|c|c|c|}
\hline & $\mathrm{N}$ & Categories & Children & Mothers \\
\hline \multirow[t]{4}{*}{ Age (years) } & \multirow[t]{4}{*}{21} & Median (p25 - p75) & $9(7-10)$ & $43(39-46)$ \\
\hline & & Min.-max. & $6-11$ & $32-50$ \\
\hline & & $6-8$ years $\mathrm{n}(\%)$ & $10(47.6 \%)$ & \\
\hline & & $9-11$ years $n(\%)$ & $11(52.4 \%)$ & \\
\hline \multirow[t]{2}{*}{ Gender N (\%) } & \multirow[t]{2}{*}{21} & Boy & $8(38.1 \%)$ & \\
\hline & & Girl & $13(61.9 \%)$ & \\
\hline \multirow[t]{2}{*}{ Body weight (kg) } & \multirow[t]{2}{*}{21} & Median (p25 - p75) & $29(26-35)$ & $69(62-81)$ \\
\hline & & Min.-max. & $18-48$ & $54-186$ \\
\hline \multirow[t]{2}{*}{ Height (cm) } & \multirow[t]{2}{*}{21} & Median (p25 - p75) & $136(127-145)$ & $168(161-172)$ \\
\hline & & Min.-max. & $122-166$ & $150-180$ \\
\hline \multirow[t]{2}{*}{ Body Mass Index $\left(\mathrm{kg} / \mathrm{m}^{2}\right)$} & \multirow[t]{2}{*}{21} & Median (p25 - p75) & $15.8(14.8-16.8)$ & $26.14(22.32-31.60)$ \\
\hline & & Min.-max. & $12.1-21.4$ & $19.96-62.15$ \\
\hline \multirow[t]{2}{*}{ Urinary creatinine $(\mathrm{mg} / \mathrm{L})$} & \multirow[t]{2}{*}{21} & Median (p25 - p75) & $898(781-1144)$ & $1025(836-1518)$ \\
\hline & & Min.-max. & $489-1768$ & $357-2085$ \\
\hline \multirow[t]{3}{*}{ Highest educational level of the family $\mathrm{N}(\%)$} & \multirow[t]{3}{*}{21} & Primary (ISCED 0-2) & $\longrightarrow$ & $0(0.0 \%)$ \\
\hline & & Secondary (ISCED 3-4) & & $3(14.3 \%)$ \\
\hline & & Tertiary (ISCED 5-6) & & $18(85.7 \%)$ \\
\hline \multirow[t]{4}{*}{ Smoking habits N (\%) } & \multirow[t]{4}{*}{21} & Daily smoker & $\longrightarrow$ & $0(0 \%)$ \\
\hline & & Occasional smoker & & $1(4.8 \%)$ \\
\hline & & Former smoker & & $5(23.8 \%)$ \\
\hline & & Non-smoker & & $15(71.4 \%)$ \\
\hline \multirow[t]{3}{*}{ ETS at home N (\%) (in former and non-smokers only) } & \multirow[t]{3}{*}{20} & Daily & $1(4.8 \%)$ & $1(5.0 \%)$ \\
\hline & & Less than daily & $0(0.0 \%)$ & $0(0.0 \%)$ \\
\hline & & Never & $20(95.2 \%)$ & $19(95.0 \%)$ \\
\hline \multirow[t]{2}{*}{ ETS elsewhere (in non-smokers only) N (\%) } & \multirow[t]{2}{*}{20} & Yes & $6(28.6 \%)$ & $6(30.0 \%)$ \\
\hline & & No & $15(71.4 \%)$ & $14(70.0 \%)$ \\
\hline \multirow[t]{2}{*}{ ETS in last 24 hours (in non-smokers only) N (\%) } & \multirow[t]{2}{*}{20} & Yes & $1(4.8 \%)$ & $2(10.0 \%)$ \\
\hline & & No & $20(95.2 \%)$ & $18(90.0 \%)$ \\
\hline \multirow[t]{3}{*}{ Use of personal care products N (\%) } & \multirow[t]{3}{*}{20} & High & $0(0 \%)$ & $11(55.0 \%)$ \\
\hline & & Moderate & $8(38.1 \%)$ & $9(45.0 \%)$ \\
\hline & & Low & $13(61.9 \%)$ & $0(0.0 \%)$ \\
\hline \multirow[t]{2}{*}{ Consumption of rice N (\%) } & \multirow[t]{2}{*}{21} & At least once a week & $3(14.3 \%)$ & $2(9.5 \%)$ \\
\hline & & Less often & $18(85.7 \%)$ & $19(90.5 \%)$ \\
\hline \multirow[t]{2}{*}{ Consumption of fish (all types) N (\%) } & 21 & Several times per week & $8(38.1 \%)$ & $7(33.3 \%)$ \\
\hline & & Once a week or less & $13(61.9 \%)$ & $14(66.7 \%)$ \\
\hline Amalgam teeth fillings N (\%) & 21 & Yes & $2(9.5 \%)$ & $17(81.0 \%)$ \\
\hline & & No & $19(90.5 \%)$ & $4(19.0 \%)$ \\
\hline PVC in house $\mathrm{N}(\%)$ & 20 & Yes & $\longrightarrow$ & $9(45.0 \%)$ \\
\hline & & No & & $11(55.0 \%)$ \\
\hline
\end{tabular}

P25: 25th percentile; P75: 75th percentile; N: number; Min.: minimum; Max.: maximum. ISCED:International Standard Classification of Education; ETS: environmental tobacco smoke; Use of personal care products (PCP) is calculated as a score based on the frequency (never to daily) of 9 PCP groups (make-up, eye make-up, shampoo, hair styling products, body lotions \& creams, fragrances, deodorant, massage oil and nail polish; PVC: polyvinyl chloride.

et al. 1995). No participants had cotinine levels near or above $50 \mu \mathrm{g} / \mathrm{g}$ creatinine. In $90.5 \%$ of mothers and $95.2 \%$ of children, the cotinine level in urine was below the LOQ of $1.2 \mu \mathrm{g} / \mathrm{L}$. The maximum value for cotinine recorded was $3.6 \mu \mathrm{g} / \mathrm{L}(4.1 \mu \mathrm{g} / \mathrm{g}$ creatinine $)$ in the mothers and $2.4 \mu \mathrm{g} / \mathrm{L}$
$(2.0 \mu \mathrm{g} / \mathrm{g}$ creatinine) in the children. These higher levels were in samples from participants who reported being exposed to tobacco smoke in the home. None of the mothers reported being regular smokers, and this was evident with extremely low levels of cotinine measured. 


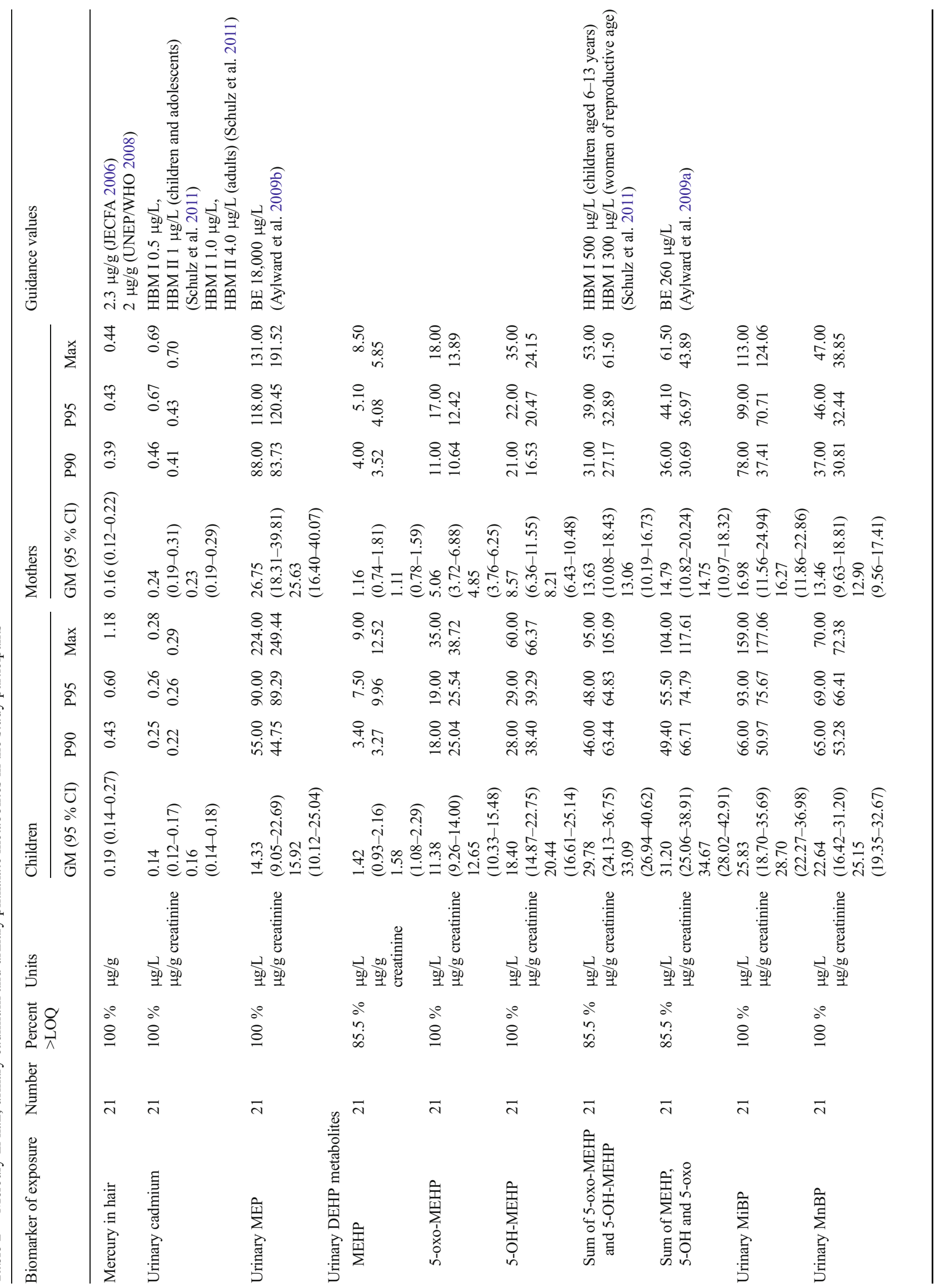


Cadmium accumulates in the kidneys and urinary cadmium reflects both recent and long-term exposure to cadmium (Agency for Toxic Substances and Disease Registry 2012). Geometric means and 90th and 95th percentiles are listed in Table 2. The maximum value for cadmium in the mothers was $0.69 \mu \mathrm{g} / \mathrm{L}(0.70 \mu \mathrm{g} / \mathrm{g}$ creatinine $)$ and $0.28 \mu \mathrm{g} / \mathrm{L}(0.29 \mu \mathrm{g} / \mathrm{g}$ creatinine $)$ in the children. The mothers' values were significantly higher than the children's values $(p=0.004)$. There was no specific difference in cadmium levels in participants who reported being exposed to tobacco smoke in the home compared to participants who reported no exposure to tobacco smoke in the home. For children, a positive association was observed between urinary creatinine and urinary cadmium levels; those with higher urinary creatinine (1000-2000 mg/L) had significantly higher cadmium levels $(p=0.001)$ than those with 300 $1000 \mathrm{mg} / \mathrm{L}$ creatinine. All the participants' measured cadmium levels were below the German Commission on Human Biomonitoring (HBM) I values for both the children and mothers. These values correspond to the concentration of a substance in human biological material below which-according to the knowledge and judgement of the German Commission on Human Biomonitoring-adverse health effects are not expected (Schulz et al. 2007, 2011).

Urinary phthalate metabolites

Exposure to the phthalates DEP, DEHP, DiBP, DnBP and $\mathrm{DBzP}$ was assessed by the measurement of specific urinary metabolites, monoesters and oxidised metabolites (MEP, MEHP, 5-oxo-MEHP, 5-OH-MEHP, MiBP, MnBP, MBzP) which are short-lived and reflect recent exposure. The results for mothers and children are shown in Table 2. All the phthalate metabolite concentrations, except for MEP, were higher in the children compared to those in the mothers. The highest metabolite levels measured in the mothers were for MEP, geometric mean $26.8 \mu \mathrm{g} / \mathrm{L}$, but they were not correlated with the children's levels. The lowest concentrations of metabolites for mothers were MEHP $1.16 \mu \mathrm{g} / \mathrm{L}$ (a weak correlation $0.43, p=$ 0.05 ) and MBzP $1.63 \mu \mathrm{g} / \mathrm{L}$ (not correlated with the children). MiBP was the highest metabolite level measured for children, geometric mean concentration $25.83 \mu \mathrm{g} / \mathrm{L}$. In both mothers and children, the urinary levels of the DEHP metabolites MEHP, 5-oxo-MEHP and 5-OH-MEHP were highly correlated (Pearson correlation coefficient $>0.70, p<0.01$ ), and the secondary metabolites 5-oxo-MEHP and 5-OH-MEHP were higher than MEHP. All the participants' measured levels were below the HBM I values for the sum of the 5-oxo-MEHP and 5-OH-MEHP (Schulz et al. 2011). 


\section{Discussion}

The UK DEMOCOPHES study recruited children (aged 6 to 11 years) and their accompanying mothers to measure exposure to cadmium, mercury, phthalates and cotinine, using human biomarker and questionnaire data. The main objective of the DEMOCOPHES pilot study was to test the feasibility of a harmonised EU HBM framework and harmonised study protocols developed by COPHES to generate comparable data.

For this pilot study, only 42 participants were recruited as the sampling process suffered from a poor response rate. A poor response rate can result in selection bias, for example, the education levels of the families who took part were mainly of tertiary $(85.7 \%)$ and higher secondary or post-secondary nontertiary education level (14.3\%). The proportion of eligible participants who agree to enter the study (the response rate) influences the validity of the inference that the sample represents the population of interest.

People who are difficult to reach and those who refuse to participate once they have been contacted tend to be different from people who enrol. The main reason given by mothers for not participating was that they did not have the time to take part. Other reasons included a reluctance to travel to a study centre and children not wanting to provide a urine sample. Understanding the public's concerns with regards to taking part in a HBM study is useful and can be addressed in future studies when preparing the information material by highlighting and addressing the issues known to be of concern. Reasons for schools not taking part was often because they were busy or were involved in other projects. Contact with potential schools needs to occur much earlier in advance to engage the school community and so that the project can be included in the school curriculum. Lessons learnt from all the participating European countries with regards to communication in recruitment and dissemination of results are discussed in Exley et al. (2014).

In the UK, communication of the results was different to the recommended approach by COPHES which was to provide individual and aggregate results. The ethical committee in the UK favoured the clinical approach of only providing individual results when health-based guidance values and interventions are available. There is much discussion in the literature about the benefits of the two approaches to dissemination of results. A more open approach is favoured for transparency and would help with community engagement (Keune et al. 2008; MorelloFrosch et al. 2009; Exley et al. 2014). Participants may have felt that there was no benefit for them taking part in the study, and this may have contributed to the poor response rate.

Hair analysis is a useful way to determine exposure to mercury through fish consumption and represents exposure over the last 2-3 months (depending on the length of hair taken). There is a wide variation in mercury levels in hair in different countries (Miklavčič Višnjevec et al. 2014), and many published studies report mercury levels in hair of pregnant women, and/or on countries where fish is a large component of the population's diet. A summary of mercury levels measured in hair samples from children and females worldwide is shown in Table 3 .

There are few population-based reference values for mercury in children's hair, and they cover different age ranges compared to our study (6-11 years old). In the DEMOCOPHES study, the Czech Republic had a lower level of mercury for children aged 6-11 years old compared to the UK. This highlights the usefulness of the DEMOCOPHES study where data are comparable. Switzerland, Denmark, Luxembourg, Sweden and Slovenia had similar levels in children compared to the UK whereas Portugal and Spain had higher levels, most likely due to their greater fish consumption (DEMOCOPHES 2013; Pirard et al. 2014; Cullen et al. 2014; Den Hond et al. 2015, Castaño et al. 2015).

In mothers, the 90th percentile (P90) was half that of the population reference values of the Flemish 2007-2008 biomonitoring study (Milieu Gezondheid 2010), and the US NHANES 1999-2000 study (McDowell et al. 2004), as shown in Table 3. Although these studies showed an increase in mercury in hair with age, the mean level of mercury measured in the mothers' hair was lower than the level measured in the children's hair; other studies have also reported no association with mercury levels in hair and age (Cordier et al. 1998; Li et al. 2008; Wranova et al. 2009). This may be due to different exposures to mercury, for example, it could have something to do with the different levels of contamination or the types of fish consumed by mothers compared to children in the UK. In children, a statistically significant increase in mercury in hair was associated with frequent consumption of fish (but not in the mothers). Anecdotal evidence suggests that in the UK, children are often given tuna to eat whereas mothers may choose a different type of fish, cod or plaice for example. In this study, data was collected on the frequency of eating all types of fish and then more specifically sea fish, shellfish and freshwater fish and other fish products. Collecting more detail on the type of fish consumed would be a useful addition to future studies of mercury to enhance exposure assessment. More specific questions such as how often the participants eat fish known to have higher levels of mercury could be included in future questionnaires; for example, shark, marlin, swordfish and tuna are known to contain higher levels of mercury than other fish (Davis et al. 2012).

Officially recognised guidelines for mercury in hair are not available so COPHES suggested using the value of $5 \mu \mathrm{g} / \mathrm{g}$ that served as a basis for the modelling of the commission (HBMC 1999), $1 \mu \mathrm{g} / \mathrm{g}$ defined as a reference dose by the US National Research Council (NRC 2000) or, the value used by DEMOCOPHES, $2.3 \mu \mathrm{g} / \mathrm{g}$ recommended by the Joint FAO/ WHO Expert Committee on Food Additives (JECFA 2006). More recently, the WHO proposed an initial screening level for further action of $2 \mu \mathrm{g} / \mathrm{g}$ hair (UNEP/WHO 2008). The 
Table 3 Mercury levels measured in hair samples from children and females worldwide

\begin{tabular}{|c|c|c|c|c|c|c|}
\hline Study population & Country/region & Period & Number & \multicolumn{2}{|c|}{ Mercury levels $(\mu \mathrm{g} / \mathrm{g})$} & Reference \\
\hline \multicolumn{7}{|l|}{ Children } \\
\hline $1-5$ years old & US & 1999-2000 & 838 & $\begin{array}{l}\text { GM (min-max) } \\
\text { P90 }\end{array}$ & $\begin{array}{l}0.12(0.10-0.12) \\
0.41\end{array}$ & $\begin{array}{l}\text { US NHANES study } \\
\text { (McDowell et al. 2004) }\end{array}$ \\
\hline 6-11 years old & Belgium & 2012 & 127 & $\begin{array}{l}\text { GM } \\
\text { P75 }\end{array}$ & $\begin{array}{l}0.2 \\
0.3\end{array}$ & (Pirard et al. 2014) \\
\hline $6-11$ years old & Ireland & 2012 & 120 & $\begin{array}{l}\text { GM (min-max) } \\
\text { P90 }\end{array}$ & $\begin{array}{l}0.097(0.082-0.114) \\
0.352\end{array}$ & (Cullen et al. 2014) \\
\hline 3-17 years old & France & 2006-2007 & 1364 & P95 & 1.20 & (Fréry et al. 2012) \\
\hline $\begin{array}{l}\text { Average age } \\
10.3 \pm 2.6 \text { years old }\end{array}$ & Mexico & $\begin{array}{l}1994-1995, \\
1997-2001, \\
2001-2004\end{array}$ & 796 & $\begin{array}{l}\text { Mean (min-max) } \\
\text { P90 }\end{array}$ & $\begin{array}{l}0.56(0.03-6.22) \\
1.12\end{array}$ & (Basu et al. 2014) \\
\hline $14-16$ years old & Belgium & 2007-2008 & & $\mathrm{P} 90$ & 0.48 & $\begin{array}{l}\text { Flemish biomonitoring study } \\
\text { (Milieu Gezondheid, 2010) }\end{array}$ \\
\hline $9-10$ years old & $\begin{array}{l}\text { Asahikawa, } \\
\text { Japan }\end{array}$ & 2008-2009 & 229 & GM (min-max) & $1.31(0.31-3.96)$ & Ilmiawati et al. 2014 \\
\hline \multicolumn{7}{|l|}{ Females } \\
\hline Mothers & Mexico & $\begin{array}{l}\text { 1994-1995, } \\
1997-2001, \\
2001-2004\end{array}$ & 796 & $\begin{array}{l}\text { Mean (min-max) } \\
\text { P90 }\end{array}$ & $\begin{array}{l}0.53(0.03-4.19) \\
1.02\end{array}$ & (Basu et al. 2014) \\
\hline Females & Belgium & 2014 & 129 & $\begin{array}{l}\text { GM } \\
\text { P75 }\end{array}$ & $\begin{array}{l}0.38 \\
0.6\end{array}$ & (Pirard et al. 2014) \\
\hline Females & Belgium & $2007-2008$ & & P90 & 0.9 & $\begin{array}{l}\text { Flemish biomonitoring study } \\
\text { (Milieu Gezondheid, 2010) }\end{array}$ \\
\hline Females & Ireland & 2012 & 120 & $\begin{array}{l}\text { GM (min-max) } \\
\text { P90 }\end{array}$ & $\begin{array}{l}0.165(0.137-0.198) \\
0.6\end{array}$ & (Cullen et al. 2014) \\
\hline Females & France & 2006-2007 & 365 & P95 & 1.74 & (Fréry et al. 2012) \\
\hline Females & US & 1999-2000 & 1726 & $\begin{array}{l}\text { GM (min-max) } \\
\text { P90 }\end{array}$ & $\begin{array}{l}0.20(0.16-0.24) \\
1.11\end{array}$ & $\begin{array}{l}\text { US NHANES study (McDowell } \\
\text { et al. 2004) }\end{array}$ \\
\hline $\begin{array}{l}\text { Pregnant women } \\
\text { frequent fish } \\
\text { consumption }\end{array}$ & Seychelles & & & Mean & 6.8 & (National Research Council 2000) \\
\hline $\begin{array}{l}\text { Pregnant women } \\
\text { frequent fish } \\
\text { consumption }\end{array}$ & Faroe islands & $1986-1987$ & 1,019 & GM (min-max) & $4.17(0.17-39.1)$ & (Grandjean et al. 2005) \\
\hline $\begin{array}{l}\text { Pregnant women, } \\
\text { frequent fish } \\
\text { consumption }\end{array}$ & $\begin{array}{l}\text { Greece, Aegean } \\
\text { Islands }\end{array}$ & & 219 & GM (min-max) & $\begin{array}{l}1.36 \\
(0.046-17.5)\end{array}$ & (Gibičar et al. 2006) \\
\hline Pregnant women & Mexico & $\begin{array}{c}1994-1995, \\
1997-2001, \\
2001-2004\end{array}$ & 371 & $\begin{array}{l}\text { Mean (min-max) } \\
\text { P90 }\end{array}$ & $\begin{array}{l}0.53(0.03-4.19) \\
1.02\end{array}$ & (Basu et al. 2014) \\
\hline $\begin{array}{l}\text { Pregnant and } \\
\text { lactating women }\end{array}$ & Slovenia & & 574 & $\begin{array}{l}\text { Median } \\
\text { (min-max) }\end{array}$ & $0.297(0.073-0.781)$ & (Miklavčič et al. 2011) \\
\hline
\end{tabular}

GM geometric mean, $P 75$ 75th percentile, $P 90$ 90th percentile, $P 9595$ th percentile, min minimum, max maximum

mercury levels recorded in the participants' samples are much lower than these reference values, and they are in accordance with current thinking from the UK Committee on Toxicity of Chemicals in Food, Consumer Products and the Environment (COT). Based on the 2006 UK total diet study of metals and other elements, mercury was only detected in the offal, fish and other vegetable groups with fish the major contributor to the population's dietary exposure to mercury (25\%) (Rose et al. 2010). The COT concluded that the current dietary exposures to mercury in the UK are unlikely to be of toxicological concern (COT 2008).
A summary of cadmium levels measured in urine samples from children and adults worldwide are given in Table 4. The children's urinary cadmium results are similar to populationbased reference values from the US NHANES study 20092010 (Centers for Disease Control and Prevention 2014). Higher cadmium levels were observed in the children who had higher levels of urinary creatinine, although the creatinine levels were within the range recommended by WHO (1996). It may not be appropriate to draw conclusions from this because of the small study number, but it has previously been identified that creatinine adjustment is not always the most 
Table 4 Cadmium levels measured in urine samples from children and adults worldwide

\begin{tabular}{|c|c|c|c|c|c|c|}
\hline Study population & Country/ region & Period & Number & \multicolumn{2}{|c|}{ Cadmium levels $(\mu \mathrm{g} / \mathrm{L})$} & Reference \\
\hline \multicolumn{7}{|l|}{ Children } \\
\hline $6-11$ years old & US & 2009-2010 & 415 & $\begin{array}{l}\text { GM }(95 \% \text { CI }) \\
\text { P90 }(95 \% \text { CI }) \\
\text { P95 }(95 \% \text { CI })\end{array}$ & $\begin{array}{l}0.06(0.05-0.06) \\
0.13(0.12-0.16) \\
0.17(0.14-0.23)\end{array}$ & $\begin{array}{l}\text { US NHANES Study } \\
\text { (Centers for Disease Control } \\
\text { and Prevention 2014) }\end{array}$ \\
\hline $6-11$ years old & Belgium & 2014 & 125 & GM & 0.04 & (Pirard et al. 2014) \\
\hline $3-14$ years old & Germany & 2003-2006 & 1734 & $\begin{array}{l}\text { GM } \\
\text { P95 }\end{array}$ & $\begin{array}{l}0.08 \\
0.22\end{array}$ & (Schulz et al. 2009) \\
\hline $3-6$ years old & Japan & 2001-2004 & 255 & GM & 1.74 & (Watanabe et al. 2013) \\
\hline $4-10$ years old & Korea & 2000 & 38 & GM & 1.33 & (Moon et al. 2003) \\
\hline 5 years old & Bangladesh & $2001-2003$ & 320 & $\begin{array}{l}\text { GM } \\
\text { P90 }\end{array}$ & $\begin{array}{l}0.37 \\
0.58\end{array}$ & (Kippler et al. 2010) \\
\hline $\begin{array}{l}\text { 6-9 years old } \\
\text { girls } \\
\text { boys }\end{array}$ & Spain & 2012 & $\begin{array}{l}126 \\
135\end{array}$ & GM $(95 \%$ CI $)$ & $\begin{array}{l}0.218(0.17-0.26) \\
0.22(0.19-0.26)\end{array}$ & (Rodriguez-Barranco et al. 2014) \\
\hline \multicolumn{7}{|l|}{ Adults } \\
\hline Females & US & 2009-2010 & 1450 & $\begin{array}{l}\text { GM }(95 \% \mathrm{CI}) \\
\text { P90 }(95 \% \mathrm{CI}) \\
\text { P95 }(95 \% \mathrm{CI})\end{array}$ & $\begin{array}{l}0.19(0.17-0.21) \\
0.74(0.62-0.88) \\
1.07(0.91-1.31)\end{array}$ & $\begin{array}{l}\text { US NHANES study (Centers for } \\
\text { Disease Control and Prevention 2014) }\end{array}$ \\
\hline Females & Belgium & 2014 & 125 & $\begin{array}{l}\text { GM } \\
\text { P75 }\end{array}$ & $\begin{array}{l}0.21 \\
0.30\end{array}$ & (Pirard et al. 2014) \\
\hline Females & Bangladesh & $2001-2003$ & 444 & $\begin{array}{l}\text { GM } \\
\text { P90 }\end{array}$ & $\begin{array}{l}0.77 \\
1.5\end{array}$ & (Kippler et al.2010) \\
\hline Females & France & 2006-2007 & 1206 & $\begin{array}{l}\text { GM } \\
\text { P95 }\end{array}$ & $\begin{array}{l}0.31 \\
0.93\end{array}$ & (Fréry N 2012) \\
\hline Females & Flanders, Belgium & $2007-2009$ & & $\mathrm{P} 90$ & 0.51 & (Milieu Gezondheid 2010) \\
\hline Adults never-smokers & Germany & 1998 & 2106 & $\begin{array}{l}\text { GM } \\
\text { P95 }\end{array}$ & $\begin{array}{l}0.18 \\
0.65\end{array}$ & $\begin{array}{l}\text { German Environmental Survey } \\
\text { (Becker et al. 2003). }\end{array}$ \\
\hline Adults & UK & 2007 & 435 & P95 & 0.90 & (Bevan et al. 2013) \\
\hline Adults & UK & 2014 & 132 & $\begin{array}{l}\text { Median } \\
\text { P95 }\end{array}$ & $\begin{array}{l}0.13 \\
0.52\end{array}$ & (Morton et al. 2014) \\
\hline
\end{tabular}

GM geometric mean, $P 75$ 75th percentile, $P 90$ 90th percentile, $P 95$ 95th percentile, 95 CI $95 \%$ confidence interval, min minimum, max maximum

appropriate method for cadmium analysis (Barr et al. 2005; Pirard et al. 2014).

The levels of urinary cadmium in the mothers were low and comparable (within $1 \mu \mathrm{g} / \mathrm{L}$ ) with the population-based reference values from a UK study (Bevan et al. 2013), the Flemish human biomonitoring program (Milieu Gezondheid 2010) and the US NHANES study 2009-2010 (Centers for Disease Control and Prevention 2014), and the German Environmental Survey value for non-smoking adults (Becker et al. 2003) shown in Table 4 . The US reference value is slightly higher than the other reference values, but it does include both smoking and nonsmoking women, whereas no mothers reported being smokers in our study as confirmed by the cotinine results.

Tobacco smoke is a known source of cadmium, and Bevan and colleagues noted little difference in levels of urinary cadmium between individuals who previously smoked compared to those who have never smoked (Bevan et al. 2013). None of the participants had high cotinine levels, which is a marker of recent exposure to tobacco smoke. For non-smokers, the main source of exposure to cadmium is through the diet (European
Food Safety Authority 2009). In our pilot study, there was a significant difference in levels of cadmium in mothers who consumed rice at least once a week $(p=0.04)$ compared to those who ate it less frequently, and the questionnaire data revealed that mothers with higher levels of cadmium in their urine samples reported to recently have consumed offal, a known source of cadmium exposure (Food Standards Agency 2009). The 2006 UK Total Diet Study recorded highest levels of cadmium in offal $(0.08 \mathrm{mg} / \mathrm{kg})$ and noted that food consumed in larger quantities makes the larger contribution to dietary exposure such as potatoes, cereals and bread (Food Standards Agency 2009). However, no children in our study reported eating offal more than once a month, and information on potatoes and bread consumption was not collected. For cereals, $90.5 \%$ of the children reported eating cereals several times a week.

Urinary cotinine represents recent exposure, none of the mothers reported being regular smokers and this was evident with extremely low levels of cotinine measured. The low exposure to environmental tobacco smoke could be due to the 
high socio-economic status of the study group (the mothers reported levels of education and income at the higher end of the scale) and/or due to the legislation to prohibit smoking in public places. There is less information available on levels of urinary cotinine in children. From this study, urinary cotinine in children from households with at least one smoker was found to be $2.0 \mu \mathrm{g} / \mathrm{L}$, similar to that reported in the German Environmental Survey IV with data collected from 2003 to 2006 in which levels of cotinine in children from households with at least one smoker were found to be $2.6 \mu \mathrm{g} / \mathrm{L}, 4.6 \mu \mathrm{g} / \mathrm{L}$ with two smokers and $6.5 \mu \mathrm{g} / \mathrm{L}$ with three or more smokers (Conrad et al. 2010).

Very low levels of the phthalate metabolites of DEP, DEHP, DiBP, DnBP and BBzP were measured in both mothers and children. Average concentrations of all the metabolites, except for MEP, were higher in the children compared to those in the mothers, which has been shown in other similar studies (Frederiksen et al. 2013; Kasper-Sonnenberg et al. 2012; Silva et al. 2004). A possible explanation for this phenomenon is higher exposure in children due to more frequent hand-mouth contact or because of unique exposure patterns in children, for example, playing with toys or exposure via food (Angerer et al. 2011). In addition, others have reported exposures to phthalates via dust and the use of flooring or wall covering containing polyvinyl chloride (PVC), particularly in children (Ait Bamai et al. 2014; Carlstedt et al. 2013). For this study, there was no significant difference in phthalate levels in children living in homes with PVC flooring or wall coverings compared to those without PVC. Alternatively, the metabolism and excretion rate of these chemicals could be different in children compared to adults, so that similar exposure patterns can lead to higher levels in the body (Kasper-Sonnenberg et al. 2012), for example, it could indicate an enhanced oxidative metabolism in children compared to adults (Hauser and Calafat 2005).

For MEP (a metabolite of DEP), higher mean values were detected in urine of the mothers compared to the children. DEP is mainly used in cosmetics and personal care products (Heudorf et al. 2007), and the questionnaire data confirmed the assumption that the mothers used personal care products and cosmetics more frequently compared to their children. Although MEP was detected in the urine samples of the mothers, the geometric mean was almost fivefold lower than the US value for females, 2009-2010 (Centers for Disease Control and Prevention 2014).

MBzP and MnBP levels were lower than the relevant population-based reference values for Germany, GerES IV study 2003-2006 for children (Becker et al. 2009) and 2006-2008 for adults (Schulz et al. 2011) and US NHANES 2009-2010 (Centers for Disease Control and Prevention 2014). MiBP levels were almost double those of the US population reference value (P90) for both children $(66.0 \mu \mathrm{g} / \mathrm{L}$ compared to $35.7 \mu \mathrm{g} / \mathrm{L})$ and adult females $(78.0 \mu \mathrm{g} / \mathrm{L}$ compared to $29.1 \mu \mathrm{g} / \mathrm{L})$ (Centers for Disease Control and Prevention 2014) but lower than the GerES study 20032006 (P95) for children $(93 \mu \mathrm{g} / \mathrm{L}$ compared to $300 \mu \mathrm{g} / \mathrm{L}$, P95) and adults $(99 \mu \mathrm{g} / \mathrm{L}$ compared to $140 \mu \mathrm{g} / \mathrm{L})$ (Schulz et al. 2011). These different levels may reflect different patterns of usage of the parent phthalates in these countries. The variability may also be due to restriction of the use of phthalates and regulations that have come into place since the other studies were published. For example, the EU banned a number of phthalates from use in plastics to which infants may be exposed in 2005, and in 2008, the US enacted similar national legislation (Kamrin 2009).

The primary metabolite of DEHP is MEHP which was measured along with the secondary oxidised metabolites 5oxo-MEHP and 5-OH-MEHP. The secondary metabolites were present at threefold to fourfold higher concentrations than MEHP (P95 5.10 $\mu \mathrm{g} / \mathrm{L}$ MEHP compared to $17.00 \mu \mathrm{g} / \mathrm{L}$ 5-oxo-MEHP and $22.00 \mu \mathrm{g} / \mathrm{L}$ for 5-OH-MEHP), in line with previous studies, which have shown higher levels of the oxidised metabolites than MEHP (Becker et al. 2004; Fromme et al. 2007). The 95th percentile reference values for 5-oxoMEHP and 5-OH-MEHP derived from the UK postal study for adults $>18$ years are two to four times higher than our results (Bevan et al. 2013). For our pilot study, first-morning urine samples were provided and phthalates have a short halflife ( $24 \mathrm{~h})$ so only recent exposure is measured via a single urine sample, and other studies have reported day-to-day variation and intra-subject variability (Fromme et al. 2007; Kasper-Sonnenberg et al. 2012). For a more detailed look at phthalate exposures in the UK population, repeat sampling would help to characterise the variation.

\section{Conclusions}

The harmonised approach, protocols and the communication strategies developed by COPHES have been tested out in the UK as part of the European pilot study, DEMOCOPHES. In the UK, exposure to cadmium, mercury, phthalates and environmental tobacco smoke was assessed in 21 children and their mothers by sampling urine and/or hair. The small study number means that the results must be interpreted with caution; however, it is reassuring to note for the participants that no results were above available health guidance values and were of no concern with regards to health. All biomarker values were similar to or below population-based reference values published by the US NHANES and Germany's GerES surveys. This project has helped to develop and test a framework for the assessment of population exposure to environmental chemical pollutants using key model compounds. The difficulties experienced in recruitment and lessons learnt from the communication strategies have led to recommendations for future EU HBM work (Fiddicke et al. 2014; Exley et al. 
2014). The framework and techniques learnt and developed here will contribute to future work on biomonitoring in the UK to determine population exposures to other environmental chemicals and will be enhanced by the ability to make international comparisons with Europe.

Acknowledgments We would like to thank the schools and the mothers and children who agreed to participate in the study. Thank you to the members of staff at Public Health England, including Julie Scott who assisted with the sampling and Gill Fisher for administration assistance, the Health and Safety Laboratory for coordinating the sample analysis, the laboratories that analysed the samples, the coordinators and project partners of COPHES and DEMOCOPHES, the work package leaders of COPHES and their teams. Updated information on the projects can be found on the project website www.eu-hbm.info.

Funding The UK DEMOCOPHES pilot study was co-funded by the European Commission DG Environment under the LIFE+ Programme (LIFE09/ENV/BE000410) and Public Health England (formerly the Health Protection Agency). DEMOCOPHES is coordinated by the Federal Public Service Health Food Chain Safety and Environment, Belgium. COPHES is coordinated by BiPRO $\mathrm{GmbH}$, Germany, with the University of Leuven, Belgium, and is funded by the European Commission DG Research in the Seventh Framework Programme (FP7/2007-2013 - No.244237).

\section{References}

Agency for Toxic Substances and Disease Registry (2012) Toxicological profile for Cadmium. Agency for Toxic Substances and Disease Registry. http://www.atsdr.cdc.gov/toxprofiles/tp.asp?id=48\&tid= 15. [Accessed 3.10.14]

Ait Bamai Y, Araki A, Kawai T, Tsuboi T, Saito I, Yoshioka E, Kanazawa A, Tajima S, Shi C, Tamakoshi A, Kishi R (2014) Associations of phthalate concentrations in floor dust and multi-surface dust with the interior materials in Japanese dwellings. Sci Total Environ 468-469: 147-157. doi:10.1016/j.scitotenv.2013.07.107

Angerer J (2008) Di (2-ethylhexyl) phthalate (DEHP) metabolites (2ethyl-5-hydroxyhexyl phthalate, 2-ethyl-5-oxohexyl phthalate, mono-(2-ethylhexyl)phthalate) in urine. In: The MAK-Collection Part IV: Biomonitoring Methods, vol 73. Wiley-VCH GmbH \& Co KGaA Weinheim

Angerer J, Aylward LL, Hays SM, Heinzow B, Wilhelm M (2011) Human biomonitoring assessment values: Approaches and data requirements. Int J Hyg Environ Health 214:348-360. doi:10.1016/j. ijheh.2011.06.002

Aylward LL, Hays SM, Gagne M, Krishnan K (2009a) Derivation of Biomonitoring Equivalents for di (2-ethylhexyl) phthalate (CAS No. 117-81-7). Regul Toxicol Pharmacol 55:249-258

Aylward LL, Hays SM, Gagne M, Krishnan K (2009b) Derivation of Biomonitoring Equivalents for di-n-butyl phthalate (DBP), benzylbutyl phthalate (BzBP), and diethyl phthalate (DEP). Regul Toxicol Pharmacol 55:259-267

Barr DB, Wilder LC, Caudill SP, Gonzalez AJ, Needham LL, Pirkle JL (2005) Urinary creatinine concentrations in the U.S. population: Implications for urinary biologic monitoring measurements. Environ Health Perspect 113:192-200

Basu N, Tutino R, Zhang Z, Cantonwine DE, Goodrich JM, Somers EC, Rodriguez L, Schnaas L, Solano M, Mercado A, Peterson K, Sanchez BN, Hernandez-Avila M, Hu H, Maria Tellez-Rojo M (2014) Mercury levels in pregnant women, children, and seafood from Mexico City. Environ Res 135C:63-69. doi:10.1016/j.envres. 2014.08.029

Becker K, Schulz C, Kaus S, Seiwert M, Seifert B (2003) German Environmental Survey 1998 (GerES III): environmental pollutants in the urine of the German population. Int J Hyg Environ Health 206:15-24

Becker K, Seiwert M, Angerer J, Heger W, Koch HM, Nagorka R, Roßkamp E, Schlüter C, Seifert B, Ullrich D (2004) DEHP metabolites in urine of children and DEHP in house dust. Int J Hyg Environ Health 207:409-417

Becker K, Conrad A, Kirsch N, Kolossa-Gehring M, Schulz C, Seiwert M, Seifert B (2007) German Environmental Survey (GerES): Human biomonitoring as a tool to identify exposure pathways. Int J Hyg Environ Health 210:267-269

Becker K, Güen T, Seiwert M, Conrad A, Pick-Fuß H, Müller J, Wittassek M, Schulz C, Kolossa-Gehring M (2009) GerES IV: Phthalate metabolites and bisphenol A in urine of German children. Int J Hyg Environ Health 212:685-692

Becker K, Seiwert M, Casteleyn L, Joas R, Joas A, Biot P, Aerts D, Castaño A, Esteban M, Angerer JN, Koch HM, Schoeters G, Den Hond E, Sepai O, Exley K, Knudsen LE, Horvat M, Bloemen L, Kolossa-Gehring M (2013) A systematic approach for designing a HBM Pilot Study for Europe. Int J Hyg Environ Health 217:312322. doi:10.1016/j.ijheh.2013.07.004

Benowitz NL (1996) Cotinine as a Biomarker of Environmental Tobacco Smoke Exposure. Epidemiol Rev 18(2):188-204

Bevan R, Jones K, Cocker J, Assem FL, Levy LS (2013) Reference ranges for key biomarkers of chemical exposure within the UK population. Int J Hyg Environ Health 216:170-174. doi:10.1016/j. ijheh.2012.03.005

Blaszkewicz M (2010) Creatinine in urine. In: Angerer JSK (ed) The MAK-Collection Part IV: Biomonitoring Methods, vol 169. Wiley-VCH GmbH \& Co KGaA, Weinheim

Carlstedt F, Jonsson BA, Bornehag CG (2013) PVC flooring is related to human uptake of phthalates in infants. Indoor Air 23:32-39. doi:10. 1111/j.1600-0668.2012.00788.x

Castaño A, Cutanda F, Esteban M, Pärt P, Navarro C, Gómez S, Rosado M, López E, López A, Exley K, Govarts E, Casteleyn L, Kolossa Gehring M, Fiddicke U, Koch HM, Angerer J, Schoeters G, Den Hond E, Sepai O, Knudsen LE, Horvat M, Aerts D, Biot P, Bloemen L, Joas A, Joas R, Diaz G, Jiménez-Guerrero JA, Pirard C. Charlier C, Katsonouri A, Hadjipanayis A, Cerna M, Krsková A, Schwedler G, Wilhelm M, Nielsen JK, Jensen JF, Rudnai P, Középesy S, Cullen E, Davidson F, Gutleb AC, Fischer ME, Ligocka D, Janasik B, Reis FM, Lupsa IO, Berglund M, Namorado S, Gurzau AE, Halzlova K, Jajcaj M, Tratnik JS, Mazej D, Larsson K, Lehmann A, Crettaz P, Lavranos G, Posada M (2015) Fish consumption patterns and hair mercury levels in children and their mothers in $17 \mathrm{EU}$ countries. Environ Res. doi:10.1016/j.envres.2014.10.029

Centers for Disease Control and Prevention (2014) Centers for Disease Control and Prevention. Fourth Report on Human Exposure to Environmental Chemicals, Updated Tables, (August, 2014). U.S. Department of Health and Human Services, Atlanta, GA

Černá M, Krsková A, Čejchanová M, Spěváčková V (2012) Human biomonitoring in the Czech Republic: An overview. Int J Hyg Environ Health 215:109-119

Cocker J, Mason HJ, Warren ND, Cotton RJ (2011) Creatinine adjustment of biological monitoring results. Occup Med 61:349-353. doi: 10.1093/occmed/kqr084

Commission of the European Communities (2003) A European Environment and Health Strategy, Communication from the Commission to the Council, the European Parliament and the European Economic and Social Committee Brussels

Conrad A, Schulz C, Seiwert M, Becker K, Ullrich D, Kolossa-Gehring M (2010) German Environmental Survey IV: Children's exposure to environmental tobacco smoke. Toxicol Lett 192:79-83 
Cordier S, Grasmick C, Paquier-Passelaigue M, Mandereau L, Weber JP, Jouan M (1998) Mercury exposure in French Guiana: levels and determinants. Arch Environ Health 53:299-303. doi:10.1080/ 00039899809605712

COT (2008) Committee on Toxicity of Chemicals in Food, Consumer Products and the Environment Statement on the 2006 UK Total Diet Study of Metals and Other Elements. http://cot.food.gov.uk/pdfs/ cotstatementtds200808.pdf. [accessed 3.10.14]

Cullen E, Evans DS, Davidson F, Burke P, Burns D, Flanagan A, Griffin C, Kellegher A, Mannion R, Mulcahy M, Ryan M, Biot P, Casteleyn L, Castano A, Angerer J, Koch HM, Esteban M, Schindler BK, Navarro C, Kolossa-Gehring M, Fiddicke U, Schoeters G, Hond ED, Sepai O, Exley K, Bloemen L, Knudsen LE, Joas R, Joas A, Aerts D (2014) Mercury Exposure in Ireland: Results of the DEMOCOPHES Human Biomonitoring Study. Int J Environ Res Public Health 11:9760-9775. doi:10.3390/ijerph110909760

Davis MA, Mackenzie TA, Cottingham KL, Gilbert-Diamond D, Punshon T, Karagas MR (2012) Rice consumption and urinary arsenic concentrations in U.S. children. Environ Health Perspect 120: $1418-1424$

DEMOCOPHES (2013) Human Biomonitoring on a European Scale, Layman's report. www.eu-hbm.info/euresult/media-corner [accessed 3.10.14]European Commission (2005) Directive 2005/84/EC Official Journal of the European Union, L334/40

Den Hond E, Govarts E, Willems H, Smolders R, Casteleyn L, KolossaGehring M, Schwedler G, Seiwert M, Fiddicke U, Castaño A, Esteban M,Angerer J, Koch HM, Schindler BK, Sepai O, Exley K, Bloemen L, Horvat M, Knudsen LB, Joas A, Joas R, Biot P, Aerts D, Koppen G, Katsonouri A, Hadjipanayis A, Krskova A, Maly M, Mørck TA, Rudnai P, Kozepesy S, Mulcahy M, Mannion R, Gutleb AC, Fischer ME, Ligocka D, Jakubowski M, Reis MF, Namorado S, Gurzau AE, Lupsa IR, Halzlova K, Jajcaj M, Mazej D, Tratnik JS, López A, López E, Berglund M, Larsson K, Lehmann A, Crettaz P, Schoeters G (2015) First steps towards harmonised human biomonitoring in Europe. Environ Health Perspect 123:255-263. doi:10.1289/ehp.1408616

Esteban M, Schindler BK, Koch HM, Jiménez-Guerrero JA, Angerer J, Rivas TC, Rosado M, Gómez S, Casteleyn L, Kolossa-Gehring M, Becker K, Schoeters G, Den Hond E, Bloemen L, Sepai O, Exley K, Horvat M, Knudsen LE, Joas A, Joas R, Aerts D, Biot P, Borošová D, Davidson F, Dumitrascu I, Fischer ME, Grander M, Janasik B, Jones K, Kašparová L, Larssen T, Naray M, Nielsen F, Hohenblum P, Pinto R, Pirard C, Plateel G, Tratnik JS, Wittsiepe J, EQUAS Reference Laboratories, Argelia Castaño (2014) Mercury analysis in hair: Comparability and quality assessment within the transnational COPHES/DEMOCOPHES project. Environ Res. doi:10. 1016/j.envres.2014.11.014

European Commission (2005) Directive 2005/84/EC of the European Parliament and of the Council of 14 December 2005 amending for the 22nd time Council Directive 76/69/EEC on the approximation of the laws, regulations and administrative provisions of the Member States relating to restrictions on the marketing and use of certain dangerous substances and preparations (phthalates in toys and childcare articles). Off J Eur Union 48:40-3

European Food Safety Authority (2009) Scientific Opinion of the Panel on Contaminants in the Food Chain on a request from the European Commission on cadmium in food. EFSA J 980:1-139. doi:10.2903/ j.efsa.2009.980

Exley K (2014) Human biomonitoring to assess environmental chemical exposures: work towards a UK framework. Perspect Public Health 134:299-301. doi:10.1177/1757913914547332

Exley K, Cano N, Aerts D, Biot P, Castelyn L, Klossa-Gehring M, Schwedler G, Horvat M, Bloemen L, Knudsen LE, Joas R, Joas A, Dewolf M, Van de Mieroop E, Katsonouri A, Hadjipanayis A, Cerna M, Krskova A, Becker K, Fiddickee U, Seiwerte M, Mørck TA, Rudnai P, Kozepesy S, Cullen E, Kellegher A, Gutleb AC,
Fischer ME, Ligocka D, Kamińska J, Namoradox S, Reis MF, Lupsa I, Gurzau AE, Halzlovaz K, Jajcai M, Mazej D, Tratnik JS, Rivas TC, López E, Berglund M, Larsson K, Sepai O (2014) Communication in a human biomonitoring study: focus group work, public engagement and lessons learnt in 17 European countries. Environ Res. doi:10.1016/j.envres.2014.12.003

Fiddicke, U., Becker, K.,Schwedler, G.,Seiwert,M., Joas, R., Joas,A., Biot, P., Aerts,D., Casteleyn,L., Dumez, B., Castaño A., Angerer, J., Koch, H.M., Esteban, M., Schoeters, G., Den Hond, E., Sepai, O., Exley K., Knudsen, L.E., Horvat, M., Bloemen, L., Katsonouri, A., Hadjipanayis, A., Cerna, M., Krskova, A., Jensen, JF.,Nielsen,J., Rudnai, P., Kozepesy, S.,Gutleb, A.C. Fischer, M.E., Ligocka, D, Kamińska,j Reis, M.F., Namorado, S., Lupsa, I., Gurzau, A.E., Halzlova,K., Mazej,D., Tratnik, J.S., Rivas,T.C., Gómez, S., Berglund,M., Larsson, L., Lehmann, A., Crettaz,P.,Dewolf,M., BurnsD., Kellegher,A., Kolossa-Gehring, M., (2014) Lessons learnt on recruitment and fieldwork from a pilot European human biomonitoring survey Environ Res. doi:10.1016/j.envres.2014.08.039

Food Standards Agency (2009) Measurement of the concentrations of metals and other elements from the 2006 UK total diet study.

Frederiksen H, Nielsen JK, Morck TA, Hansen PW, Jensen JF, Nielsen O, Andersson AM, Knudsen LE (2013) Urinary excretion of phthalate metabolites, phenols and parabens in rural and urban Danish mother-child pairs. Int J Hyg Environ Health 216:772-783. doi:10. 1016/j.ijheh.2013.02.006

Fréry N SA, Garnier R, Zeghnoun A, Falq G, Guldner L. (2012) Exposure of the French population to environmental pollutants Environmental components of the French National Survey on Nutrition and Health - Initial results. French Institute for Public Health Surveillance, Saint-Maurice (Fra) http://opac.invs.sante.fr/ doc num.php?explnum id=6864Fréry N, Saoudi A, Garnier R, Zeghnoun A, Falq G. Exposition de la population françaiseaux substances chimiques de l'environnement. Saint-Maurice: Institut de veillesanitaire; 201158 [Available from http://www.invs.sante.fr].

Fromme $\mathrm{H}$ et al (2007) Occurrence and daily variation of phthalate metabolites in the urine of an adult population. Int J Hyg Environ Health 210:21-33

Gibičar D, Horvat M, Nakou S, Sarafidou J, Yager J (2006) Pilot study of intrauterine exposure to methylmercury in Eastern Aegean islands, Greece. Sci Total Environ 367:586-595

Golding J, Steer CD, Hibbeln JR, Emmett PM, Lowery T, Jones R (2013) Dietary Predictors of Maternal Prenatal Blood Mercury Levels in the ALSPAC Birth Cohort Study. Environ Health Perspect 121:1214 1218. doi:10.1289/ehp. 1206115

Grandjean P, Budtz-Jorgensen E, Jorgensen PJ, Weihe P (2005) Umbilical cord mercury concentration as biomarker of prenatal exposure to methylmercury. Environ Health Perspect 113:905-908

Hauser R, Calafat AM (2005) Phthalates Human Health Occup Environ Med 62:806-818. doi:10.1136/oem.2004.017590

HBMC (1999) Human Biomonitoring Commission of the German Federal Environment Agency (HBMC) Substance monograph: mercury - Reference values and human biomonitoring (HBM) levels. Institute for Water, Soil and Air Hygiene of the German Federal Environmental Agency. Bundesgesundheitsbl Gesundheitsforsch - Gesundheitsschutz 42(6):522-532. SpringerVerlag [In German]

Heudorf U, Mersch-Sundermann V, Angerer J (2007) Phthalates: Toxicology and exposure. Int J Hyg Environ Health 210:623-634

Ilmiawati C, Yoshida T, Itoh T, Nakagi Y, Saijo Y, Sugioka Y, Sakamoto M, Ikegami A, Ogawa M, Kayama F (2014) Biomonitoring of mercury, cadmium, and lead exposure in Japanese children: a crosssectional study. Environ Health Prev Med. doi:10.1007/s12199014-0416-4

JECFA, (2006). Compendium of Food Additive Specifications: Joint FAO/WHO Expert Committee on Food Additives (JECFA): 67th Meeting 2006. Food \& Agriculture Org. 
Joas RCL, Biot P, Kolossa-Gehring M, Castano A, Angerer J, Schoeters G, Sepai O, Knudsen LE, Joas A, Horvat M, Bloemen L (2012) Harmonised human biomonitoring in Europe: Activities towards an EU HBM framework. Int J Hyg Environ Health 215:172-175

Kamrin MA (2009) Phthalate risks, phthalate regulation, and public health: a review. J Toxicol Environ Health B Crit Rev 12:157174. doi:10.1080/10937400902729226

Kasper-Sonnenberg M, Koch HM, Wittsiepe J, Wilhelm M (2012) Levels of phthalate metabolites in urine among mother-child-pairs Results from the Duisburg birth cohort study, Germany. Int J Hyg Environ Health 215(3):373-382. doi:10.1016/j.ijheh.2011.09.004, 215

Keune, H., Morrens, B., Loots, I., (2008). Risk communication and human biomonitoring: which practical lessons from the Belgian experience are of use for the EU perspective? Environ Health. 7 Suppl 1, S11. doi:10.1186/1476-069×-7-S1-S11

Kippler M, Nermell B, Hamadani J, Tofail F, Moore S, Vahter M (2010) Burden of cadmium in early childhood: Longitudinal assessment of urinary cadmium in rural Bangladesh. Toxicol Lett 198:20-25

Koch HM, Rossbach B, Drexler H, Angerer J (2003) Internal exposure of the general population to DEHP and other phthalates - determination of secondary and primary phthalate monoester metabolites in urine. Environ Res 93:177-185

Li P, Feng X, Qiu G, Shang L, Wang S (2008) Mercury exposure in the population from Wuchuan mercury mining area, Guizhou, China. Sci Total Environ 395:72-79

McDowell MA et al (2004) Hair mercury levels in U.S. children and women of childbearing age: reference range data from NHANES 1999-2000. Environ Health Perspect 112:1165-1171

Miklavčič Višnjevec A, Kocman D, Horvat M (2014) Human mercury exposure and effects in Europe. Environ Toxicol Chem 33:12591270. doi: $10.1002 /$ etc. 2482

Miklavčič A, Cuderman P, Mazej D, Snoj Tratnik J, Krsnik M, Planinsek P, Osredkar J, Horvat M (2011) Biomarkers of low-level mercury exposure through fish consumption in pregnant and lactating Slovenian women. Environ Res 111:1201-1207. doi:10.1016/j. envres.2011.07.006

Milieu Gezondheid (2010) Flemish Human biomonitoring programme 2007-2011. Flemish Centre of Expertise for Environment and Health.

Moon CS, Paik JM, Choi CS, Kim DH, Ikeda M (2003) Lead and cadmium levels in daily foods, blood and urine in children and their mothers in Korea. Int Arch Occup Environ Health 76:282-288. doi: 10.1007/s00420-002-0415-4

Morello-Frosch, R., Brody, J. G., Brown, P., Altman, R. G., Rudel, R. A., Perez, C., (2009). Toxic ignorance and right-to-know in biomonitoring results communication: a survey of scientists and study participants. Environ Health. 8, 6. doi:10.1186/1476-069×-8-6

Morton, J., Tan, E., Leese, E., Cocker, J., 2014. Determination of 61 elements in urine samples collected from a non-occupationally exposed UK adult population. Toxicol Lett. 10.1016/ j.toxlet.2014.08.019

Müller M (2005) Cotinine. In: Angerer JSK-H (ed) Analysis of Hazardous Substances in Biological Materials, vol 53. Wiley-VCH $\mathrm{GmbH} \& \mathrm{Co} \mathrm{KGaA}$, Weinheim

National Research Council (2000) Toxicological Effects of Methylmercury. The National Academies Press, Washington, DC

Pirard C et al (2014) Hair mercury and urinary cadmium levels in Belgian children and their mothers within the framework of the COPHES/ DEMOCOPHES projects. Sci Total Environ 472:730-740. doi:10. 1016/j.scitotenv.2013.11.028

Riboli E, Haley N, Tredaniel J, Saracci R, Preston-Martin S, Trichopoulos D (1995) Misclassification of smoking status among women in relation to exposure to environmental tobacco smoke. Eur Respir J 8:285-290

Rodriguez-Barranco M, Lacasana M, Gil F, Lorca A, Alguacil J, Rohlman DS, Gonzalez-Alzaga B, Molina-Villalba I, Mendoza R, Aguilar-Garduno C (2014) Cadmium exposure and neuropsychological development in school children in southwestern Spain. Environ Res 134C:66-73. doi:10.1016/j.envres.2014.06.026

Rose M, Baxter M, Brereton N, Baskaran C (2010) Dietary exposure to metals and other elements in the 2006 UK Total Diet Study and some trends over the last 30 years. Food Addit Contam Part A Chem Anal Control Expo Risk Assess 27:1380-1404. doi:10. 1080/19440049.2010.496794

Schindler BKE M, Koch HM, Castano A, Koslitz S, Canas A, Casteleyn L, Kolossa-Gehring M, Schwedler G, Schoeters G, Hond ED, Sepai O, Exley K, Bloemen LH M, Knudsen LE, Joas A, Joas R, Biot P, Aerts D, Lopez A, Huetos O, Katsonouri A, Maurer-Chronakis K, Kasparova L, Vrbik K, Rudnai P, Naray M, Guignard CF ME, Ligocka D, Janasik B, Reis MF, Namorado S, Pop C, Dumitrascu I, Halzlova K, Fabianova E, Mazej D, Tratnik JS, Berglund M, Jonsson B, Lehmann A, Crettaz PFH, Nielsen F, McGrath H, Nesbitt I, De Cremer K, Vanermen G, Koppen G, Wilhelm M, Becker K, Angerer J (2014) The European COPHES/ DEMOCOPHES project: Towards transnational comparability and reliability of human biomonitoring results. Int J Hyg Environ Health 217:653-661. doi:10.1016/j.ijheh.2013.12.002

Schoeters G et al (2012) Concept of the Flemish human biomonitoring programme. Int J Hyg Environ Health 215:102-108. doi:10.1016/j. ijheh.2011.11.006

Schramel PaW I (1999) Antimony, Lead, Cadmium, Platinum, Mercury, Tellurium, Thallium, Bismuth, Tungsten, Tin - ICP-MS collective method. In: Angerer J SK (ed) Analysis of Hazardous Substances in Biological Materials, vol 6. Wiley-VCH GmbH \& Co KGaA, p 79

Schulz C, Angerer J, Ewers U, Kolossa-Gehring M (2007) The German Human Biomonitoring Commission. Int J Hyg Environ Health 210: 373-382

Schulz C, Angerer J, Ewers U, Heudorf U, Wilhelm M (2009) Revised and new reference values for environmental pollutants in urine or blood of children in Germany derived from the German Environmental Survey on Children 2003-2006 (GerES IV). Int J Hyg Environ Health 212:637-647

Schulz C, Wilhelm M, Heudorf U, Kolossa-Gehring M (2011) Update of the reference and HBM values derived by the German Human Biomonitoring Commission. Int J Hyg Environ Health 215:26-35

Silva M, Barr DB, Reidy JA, Malek NA, Hodge CC, Caudill SP, Brock JW, Needham LL, Calafat AM (2004) Urinary levels of seven phthalate metabolites in the U.S. population from the National Health and Nutrition Examination Survey (NHANES) 1999-2000. Environ Health Perspect 112:331-338

Taylor CM, Golding J, Hibbeln J, Emond AM (2013) Environmental Factors Predicting Blood Lead Levels in Pregnant Women in the UK: The ALSPAC Study. PLoS One 8:e72371. doi:10.1371/ journal.pone. 0072371

UNEP/WHO (2008) United Nations Environment Programme (UNEP) and World Health Organization (WHO) Guidance For Identifying Populations At Risk from Mercury Exposure. Geneva, Switzerland

Watanabe T, Nakatsuka H, Shimbo S, Yaginuma-Sakurai K, Ikeda M (2013) High cadmium and low lead exposure of children in Japan. Int Arch Occup Environ Health 86:865-873. doi:10.1007/s00420-012-0821-1

WHO (1996) Biological Monitoring of Chemical Exposure in the Workplace Guidelines. World Health Organization, Geneva

Wranova K, Cejchanova M, Spevakova V, Korunova V, Vobecky M, Spevacek V (2009) Mercury and methylmercury in hair of selected groups of Czech population. Cent Eur J Public Health 17:36-40 